\title{
Developing weighting system for refurbishment building assessment scheme in Malaysia through analytic hierarchy process (AHP) approach
}

\begin{abstract}
The building industry has an undeniable impact on the natural environment. Evidence shows that existing buildings make a significant contribution to energy demand and $\mathrm{CO}_{2}$ emissions. Refurbishing existing buildings offers significant opportunities to reduce energy consumption and $\mathrm{CO}_{2}$ emissions. The Malaysian government has set a target to retrofit 100 government buildings in order to contribute to the country's commitment to reduce the $\mathrm{CO}_{2}$ emissions intensity of gross domestic product by $45 \%$ by 2030 . However, there is no specific sustainability assessment scheme targeted at building refurbishment in Malaysia. Thus, this research aims to support the development of a refurbishment sustainability assessment scheme for Malaysia. The Analytic Hierarchy Process (AHP) method was adopted in order to rank assessment themes and identify the priorities of the study's participating stakeholders. The outcome is the Malaysian Refurbishment Assessment Scheme (MRAS), which includes a set of weightings and a classification system for the selected assessment themes and subthemes. The methods and findings can be adapted for use by other practitioners to develop building assessment schemes in order to pursue the goals of sustainable development through refurbishment.
\end{abstract}

Keywords: Analytic Hierarchy Process; Assessment Scheme; Assessment Themes; Refurbishment; Sustainability; Non-domestic buildings 


\section{Introduction}

The impacts of greenhouse gas emissions such as carbon dioxide $\left(\mathrm{CO}_{2}\right)$ on global warming and climate change have led to international demands for immediate action to reduce emissions, and thus their impacts on the natural environment (UNFCCC, 2015). Buildings are often considered as a key focus in promoting sustainable development due to several reasons. First, buildings are a major source of $\mathrm{CO}_{2}$ emissions (Raslanas et al., 2013) because they release one third of global greenhouse gas emissions (UNEP, 2015). In addition, buildings consume $40 \%$ of the world's energy supply, $25 \%$ of the world's water use, $40 \%$ of the resources used (UNEP, 2015). This brings significant impacts on the environment as buildings consume resources throughout their lifecycle not only during the construction period (Yang et al., 2013). Second, the construction industry is closely related to the daily lives of people as they spend most of their time within the buildings, which has both longterm consequences on the health of people and their social impacts. In view of that, the impact of buildings on both of the environment and society is sizable if they are unsustainably designed, built, operated and maintained.

The Malaysian government has set a goal of reducing the carbon intensity of gross domestic product (GDP) by $45 \%$ by 2030 to reduce $\mathrm{CO}_{2}$ emissions and save energy (The Malaysian Reserve, 2015). A dramatic increase in the energy efficiency of buildings is essential to achieve this goal. This requires both existing buildings as well as new build to improve their energy performance. However, the majority of the national building stocks are existing buildings rather than new buildings. A study conducted by Ahmed and Nayar (2008) found that existing buildings in Malaysia could achieve a reduction of $15 \%$ to $25 \%$ in energy consumption through energy efficient practices. Pombo et al. (2015) stated that refurbishing existing buildings is a potential area for reducing energy consumption. Therefore, existing buildings could make a significant contribution to the government's goal in view of their high energy saving potential. The refurbishment of existing buildings can play a crucial role in achieving wider sustainability objectives (Zhou et al., 2016).

The terms refurbishment and retrofit are often used interchangeably to represent an opportunity to upgrade existing buildings for their on-going life. Retrofit refers to installing or replacing building fabric or services to a building or a single measure such as fitting insulation to an external wall; on the contrary, refurbishment can be defined as the use of multiple sustainable fabric measures to the entire building or an entire room (NRC, 2011). 
Retrofit is typically applied to describe non-intrusive system upgrades, or to add new elements to existing systems. By contrast, refurbishment often involves a wide range of improvement works such as major alterations to a fabric or services at the entire building level. While all improvements work can be conducted sustainably, the nature of the work undertaken as part of a refurbishment or retrofit project will determine the degree of energy and thus $\mathrm{CO}_{2}$ savings that can be achieved.

Building refurbishment is growing rapidly across the world. In the United Kingdom, approximately 28 million buildings must be refurbished by the end of 2050 to meet national carbon reduction targets $(\mathrm{CIOB}, 2011)$. The improvement of the energy efficiency of existing buildings will substantially reduce their carbon emissions by reducing demand for fossil fuels. In the United States, the government has provided taxation benefits to promote existing building refurbishment (DOE, 2010; Lester, 2013). In Japan, solar PV systems are highly recommended and encouraged to be used in existing buildings (Chowdhury, 2014). In China, there are 20 billion $\mathrm{m}^{2}$ of old buildings that need to be retrofitted and upgraded to save energy, reduce emissions and conserve resources (Yang et al., 2013). The policies by international governments indicate that refurbishing existing buildings is an important part of their emission reduction plans.

Refurbishment is also gaining importance in the Malaysian construction industry. An increasing number of old buildings in Malaysia exist (Rahmat et al., 2003), which make refurbishment an alternative solution to demolition and rebuilding. Refurbishment can improve the building conditions, prolong the building lifecycle, improve thermal comfort, maintain a healthy working environment, and increase the building value (Mickaityte et al., 2008). In the Eleventh Malaysia Plan (2016-2020), refurbishing 100 Government buildings is one of the targets of the government (EPU, 2015). Thus, refurbishment of existing buildings is a potential strategy for Malaysia to improve energy efficiency of existing buildings (Ahmed and Nayar, 2008; Zhou et al., 2016; Pombo et al., 2015). In order to facilitate and promote sustainable refurbishment, an assessment scheme for building refurbishment is critical to guide, measure, and rate refurbishment projects in Malaysia.

This paper describes the development of the weightings for a refurbishment sustainability assessment scheme in Malaysia. Following this introduction, section 2 provides an overview of existing refurbishment assessment schemes and sustainability assessment themes. Section 3 outlines how appropriate assessment themes for a Malaysian specific refurbishment scheme are identified. Section 4 presents the research methods applied to 
weight the assessment themes. Section 5 elucidates the development of the weighting system, rating score, and rating classification. Section 6 gives the results and discussion, and Section 7 concludes this paper.

\section{Refurbishment assessment scheme}

The topic of sustainability and building environmental assessment schemes has become a popular research area. The widely known schemes to assess buildings include the Building Research Establishment Environmental Assessment Methodology (BREEAM) in the United Kingdom, the Leadership in Energy and Environmental Design (LEED) in the United State, the Sustainable Building (SB) Tool in Canada, the Green Star in Australia, the Building Environmental Assessment Method (BEAM) Plus in Hong Kong, the Comprehensive Assessment System for Built Environment Efficiency (CASBEE) in Japan, the Sustainable Building Assessment Tool (SBAT) in South Africa, the Green Building Index (GBI) in Malaysia and the Green Building Labelling System in Taiwan. Numerous research has been conducted by a number of authors to compare these assessment schemes (Ding, 2008; Haapio and Viitaniemi, 2008; Lee, 2013; Michael et al., 2014; Sinou and Kyvelou, 2006). Most of the literature reviewed focuses on comparison of assessment schemes in terms of their characteristics, assessment trends and parameters, strengths, weaknesses, and limitations.

Several authors have proposed and developed new environmental assessment schemes for their country. Alyami and Rezgui (2012) examined the most prominent assessment schemes to develop a potential new scheme that is suited to Saudi Arabia. Ali and Nsiarat (2009) developed a green building rating system for residential units in Jordan. In addition, many studies of neighbourhood sustainability tools have also been performed rather than individual building sustainability tools (Komeily and Srinivasan, 2015; Sharifi and Murayama, 2013; Sharifi and Murayama, 2015). It is noticeable that there is a dearth of research on developing an assessment scheme for refurbishment projects. A number of countries such as the United Kingdom, Japan, and Taiwan, have developed individual refurbishment schemes. In the United Kingdom, the Building Research Establishment (BRE) have developed a specific refurbishment and fit-out scheme in 2015, which targets building refurbishment projects called BREEAM Refurbishment (BREEAM, 2015). The Green Building Council in Japan also introduced a refurbishment tool called CASBEE Renovation 
for refurbishment assessment (CASBEE, 2015). In Taiwan, the local government developed the Ecology, Energy Saving, Waste Reduction and Health Renovation (EEWH-RN) in 2011 in view of the importance of refurbishment (Chang et al., 2012; GBL, 2013). These refurbishment schemes act as a yardstick to measure the performance of refurbished buildings. However, environmental assessment tools capable of diagnosing the best practice for building refurbishment for Malaysia are lacking. The types of environmental and social criteria and their relative importance can differ between countries, particularly those with different resources and climates. For example, the amount of water use may be of differing importance in different areas of the world.

In Malaysia, two assessment rating tools are currently being used, namely, the Green Building Index (GBI) and the Malaysian Carbon Reduction and Environmental Sustainability Tool (MyCrest). These tools are designed to assess new and existing buildings. Although they can be used to assess refurbished buildings, but they do not cover certain criteria sufficiently and comprehensively for assessing refurbished buildings. For example, they do not cover assessment themes, such as the quality of services (such as space efficiency and flexibility, and building security), economics, social and cultural aspects (Kamaruzzaman et al., 2016). Furthermore, as confirmed through the Delphi approach conducted for this study, existing assessment sub-themes, such as site selection and contaminated land, are also inapplicable for refurbishment schemes where the location is already fixed. Chang et al. (2012) criticized that using a single assessment tool to evaluate various types of buildings, such as newly built, refurbishment, residential, or community, is inadequate. Therefore, it is necessary to develop an assessment tool specifically for building refurbishment assessment that reflects the environmental and social priorities in Malaysia. The current study aims to propose a refurbishment scheme to assess non-domestic buildings in Malaysia.

Refurbishment appraisal schemes help building owners improve their existing buildings, to enhance their image, and they are also useful for the government and policy makers in raising public awareness and promoting sustainable refurbishment. Thus, the developed refurbishment scheme can be used by the government and professional bodies to assess refurbished buildings. It will be a tool in enhancing the sustainability of the refurbishment sector of Malaysia, to achieve the target reduction of $45 \%$ in carbon emissions per unit of GDP. In addition, the developed assessment scheme can also be referred to by other countries without their own refurbishment assessment scheme, such as Singapore, Australia, and Hong Kong. Malaysia and other countries can start improving the 
environmental and social performance of existing buildings by redesigning them instead of demolishing them. This process can improve the energy performance, lower carbon emissions, and reduce the operating costs of the buildings as well as additional outcomes encouraged through the scheme.

\section{Initial development of the refurbishment assessment scheme: Assessment themes and sub-themes}

The initial development of the refurbishment assessment scheme is discussed in the following sub-section, which consists of (a) a literature review, and (b) applying a Delphi approach to select the applicable assessment themes and sub-themes.

\subsection{Literature review}

The initial step in developing this assessment scheme is to identify the assessment themes applicable to non-domestic building refurbishment for the Malaysian built environment. In this study, an assessment theme was defined as a broad sustainability topic, and sub-theme was interpreted as an indicator or set of indicators that can be used to assess a refurbishment project's performance under the assessment theme (Sharifi and Murayama, 2013). For example, in this study, "water" is one of the assessment themes, and it includes "water consumption" as a sub-theme that can be measured by indicators such as "reducing potable water usage through providing efficient sanitary fittings" or "water recycling".

Cole (2005) suggests that the development process should begin with a comparative study of prominent assessment schemes. Hence, this study selected and reviewed the prominent assessment schemes that appear frequently in literature from various countries, namely, BREEAM (Building Research Establishment Environmental Assessment Methodology) (BREEAM, 2015), LEED (Leadership in Energy and Environmental Design) (USGBC, 2011), CASBEE (Comprehensive Assessment System for Built Environment Efficiency) (CASBEE, 2015), BEAM (Building Environmental Assessment Method) Plus (HKGBC, 2011), HQE (Haute Qualité Environnementale) (HQE, 2013), GBLS (Green Building Labelling System) (GBL, 2013), Green Mark (BCA, 2012), Green Star (GBCA, 2014), GBI (GBI, 2011) and MyCrest (CIDB, 2013). Limited assessment schemes are 
dedicated to refurbishment (BREEAM, CASBEE, and GBLS), and the majority use either new (LEED, BEAM Plus, HQE, Green Star, MyCrest) or existing building (Green Mark and GBI) versions to assess refurbishment works.

A comprehensive review was conducted and a preliminary list of assessment themes and sub-themes was collected from various studies (Alyami and Rezgui, 2012; Ding, 2008; Haapio and Viitaniemi, 2008; Lee, 2013; Michael et al., 2014; CSI, 2013, Tanguay et al., 2010). The preliminary list was compared with the selected individual assessment schemes to consolidate it. As assessment schemes are evolving rapidly, this approach ensured that all related and latest assessment themes and sub-themes are identified. Thus, an updated and final list of assessment themes and sub-themes was generated. The literature review identified 14 common assessment themes, namely, management, sustainable site, transport, indoor environmental quality (IEQ), water, waste, material, energy, pollution, innovation, economics, social, cultural, and the quality of services (Kamaruzzaman et al., 2016). A total of 113 assessment sub-themes were identified and compiled from the literature from the 14 assessment themes. The process of generating the assessment themes and sub-themes is illustrated in Figure 1.

\section{Insert Figure 1}

\subsection{Delphi approach}

This study adopted a Delphi approach to select assessment themes and sub-themes for refurbishment projects that are applicable to the Malaysian built environment due to several reasons. First, this approach is suitable because building assessment themes are considered multi-dimensional and require a consensus-based approach (Chew and Das, 2008). Second, Delphi is an iterative process that requires several rounds of survey to be conducted with a group of "experts" in the research field. This process allows a deeper understanding of the research issue, unlike a questionnaire survey, where randomly selected respondents cannot provide accurate replies to the questions. Third, compared with the participants in a focus group discussion, the participants in a Delphi survey are anonymous, thereby reducing bias and group pressure. 
To initiate the Delphi process, a questionnaire to assess participant's views on the 14 assessment themes and 113 assessment sub-themes identified from the literature review was designed. The questionnaire included a five-point Likert scale to record the participant's ranking of the level of importance of each of the themes and sub-themes from "not important" to "very important". The Delphi process consists of three rounds of survey using iterations of the questionnaire. In the first round, the experts were required to rank the assessment themes and sub-themes; a brief explanation of each of the main criteria was given. The rank-order of each theme and sub-theme was then produced from the mean values to establish a preliminary priority. In the second round, a questionnaire giving the criteria and ratings summarized from the previous round was administered, which allowed the anonymous experts to view the results from the first round and reassess their ratings if necessary. The final outcomes of this round were summarized and again distributed in a third round.

The selection of Delphi experts is guided by the knowledge, experience, professional qualifications and background of the experts in the research field which is capable to contribute useful insights to the research issue (Loo, 2002). Moreover, willingness to participate in the Delphi approach is also one of the important elements as it involves few rounds of survey to achieve the consensus (Oh, 1974; Pill, 1971). Thus, ten Delphi experts (architects, engineers, project managers and building surveyors) were selected based on their accreditation as GBI facilitators with at least ten years of experience in the construction industry and possesses relevant knowledge on the refurbishment and sustainability assessment, and whom are willing to participate and commit to the Delphi process. The participants were chosen from different backgrounds to obtain a range of perspectives from different professions, while at the same time ensuring they had an awareness of sustainable buildings through their involvement with the GBI. The Delphi process resulted in 14 (from 14) assessment themes and 101 (out of 113) assessment sub-themes remaining in the proposed refurbishment assessment scheme. Twelve assessment sub-themes were removed from the list as the sub-themes' mean score was less than 3 out of 5 which means they were regarded as less applicable by the Delphi experts (Alyami et al., 2013; Garg et al., 2012). The twelve removed were site selection, contaminated land, electromagnetic pollution, biological contamination, de-odorising devices, grey water recycling, cooling tower water use, material ingredient, Nitrogen oxides (NOx) emissions, wind pollution, regional priority, and improved streetscapes. In order to verify the Delphi results, qualitative interviews were conducted with seven industry experts (architects and engineers) who have at least 10 years of working 
experience in the industry and practical experience in refurbishment projects. The interview results showed that the existing schemes should be complemented by adding the relevant assessment themes that identified by the Delphi experts as important such as quality of services and economics, which are currently missing, from GBI and MyCrest. Most of the interviewees agreed with the elimination of the 12 assessment sub-themes because they were inapplicable to the Malaysian context. For example, NOx emission is inapplicable in Malaysia as buildings generally use electricity as the main energy source rather than fuel combustion, therefore the buildings do not release NOx emissions.

Following the interviews, the final listed assessment themes and sub-themes were confirmed as applicable to the Malaysian built environment for refurbishment assessment. In the next stage, the Analytical Hierarchy Process (AHP) was applied to define the relative importance of each assessment theme and sub-theme, with specific weightings.

\section{$4 \quad$ Research methodology}

AHP was adopted to develop a suitable weighting system by prioritizing and assigning the important weightings for the assessment themes. AHP developed by Thomas Saaty (1980), is known as a structured multi-attribute decision method, and it is useful for decision makers in formulating and analysing decisions. This method is based on pairwise comparisons and allows the relative assessment and prioritization of alternatives.

Numerous studies have used the AHP method to prioritize selection criteria for an intelligent building system (Wong and Li, 2008; Alwaer and Clements-Croome, 2010), to rate and select sustainability indicators for public transportation (Kumar et al., 2015), for procurement selection (Cheung et al., 2001), and for contractor selection (Al-Harbi, 2001; Fong and Choi, 2000). Thus, the application of AHP has become a popular research method in various fields for assessing, rating, and determining the importance weightings for selection indicators or criteria.

4.1 Application of the AHP method to develop a weighting system for the assessment themes 
AHP is used to allocate weights and rate the selected assessment themes for the refurbishment assessment scheme. This method can distinguish the important themes from the other themes by assigning numerical weights representing the relative importance of each assessment theme. This study adopted a five-stage AHP (Saaty, 1980) as displayed in Figure 2. The AHP methodology is based on the following three principles: (1) principles of decomposition (stages 1 and 2), which structure the problem into its constituent parts by building a hierarchical model to identify the focus of the problem, criteria, sub-criteria, and alternatives; (2) comparative judgment (stage 3) which involve the pairwise comparison of criteria to establish participants' priorities; and (3) synthesis of the priorities into an overall rating (stages 4 and 5) (Ali et al., 2009; Aminbakhsh et al., 2013).

\section{Insert Figure 2}

Following stage 1, the research problem and objectives were defined. The research problem in this study was to develop a weighting system for the assessment themes to be included in a Malaysian Refurbishment Assessment Scheme (MRAS), and the objective was to prioritise and assign the important weightings for each of the assessment themes. The problem was broken down into a hierarchal structure at stage 2. An AHP model was developed to break down the complex problems into manageable elements. Multiple hierarchical levels were generated. The top level of the hierarchy model was defined as the goal of the problem to determine the scope of the subject matter. The second level involved categories, and criterion levels were further divided. For this study, the top level was the prioritization of the assessment themes of the refurbishment, which was followed by the main assessment themes and the assessment sub-themes at the lowest level.

In stage 3, the pairwise comparison employed a mathematical structure that was built to conduct a pair comparison of each category over another category (Saaty, 1994). Criteria were compared pair wisely with respect to the project goal. A judgmental matrix (A) was formed, in which each entry $a_{i j}$ in the matrix was built by comparing the row element $A_{i}$ with the column element $A_{j}$ (Ramanathan, 2001):

$$
A=\left(a_{i j}\right)(i, j=1,2, \ldots, \text { the number of criteria })
$$


A nine-point scale was utilised to transform the respondent's judgments into numerical quantities that represent the values of $\mathrm{a}_{\mathrm{ij}}$ (Saaty, 1994). The scale was adopted to rate the relative importance of the assessment themes, as shown in Table 1. The nine-point scale showed the level of relative importance by numbers $1,3,5,7$, and 9 , which indicated equal, moderate, strong, very strong, and extreme level of the theme's importance to the survey respondents. The intermediate values were represented by $2,4,6$, and 8 .

\section{Insert Table 1}

Once the judgmental matrix was formed, the local priorities were then obtained, and the consistency of the outcome was determined. In order to avoid inconsistencies, a consistency ratio (CR) was calculated at stage 4 to measure the degree of contradictions in the judgment of survey respondents (Saaty, 1980). Any inconsistencies appearing during the selection of themes were avoided through computing a consistency level of each matrix. The CR was calculated using the formula (Saaty, 1982).

Consistency ratio $(\mathrm{CR})=$ Consistency index $(\mathrm{CI}) /$ Random index $(\mathrm{RI})$

where $C I=(\lambda \max -n) /(n-1), \lambda_{\max }=$ approximation of the maximum eigenvalue, $n=$ number of elements, and RI = the consistency index of a randomly generated reciprocal matrix within a scale of 1 to 9. Saaty (1994) set the acceptable consistency index as 0.10 . If the consistency ratio is lower than 0.10 , then the weight results are valid. However, if the consistency ratio is larger than 0.10 , then the results are inconsistent and are thus discarded. For this study, the consistency ratio was calculated automatically by Expert Choice software. Finally, stage 5 identified the weighting score for each of the themes. The AHP method could transform the respondent's subjective judgment into a quantitative analysis, which denoted numerical values by using Expert Choice software (Ali et al., 2009; Saaty, 2000). Weighting priorities were calculated by comparisons between two assessment themes according to the nine-point scale, as shown in Table 1. The weighting of each assessment themes could be estimated by calculating the principal of eigenvector $w$ of matrix A as follows (Saaty, 1980, 2000):

$$
A w=\lambda \max w
$$


When vector $w$ was normalised, the vector of the priorities of the assessment themes was generated with respect to the goal. The weighting coefficient could be easily calculated by the Expert Choice software.

\subsection{Questionnaire design and data collection for the AHP method}

This research used a questionnaire survey to collect the data required to apply the AHP. The survey was designed and conducted to prioritise and assign the importance weightings for the assessment themes. The final list of the assessment themes and sub-themes was incorporated into the questionnaire.

The ten experts who participated in the Delphi survey were asked to take part in the weighting questionnaire because the AHP method relies on the expert judgment. A large sample is not mandatory for the AHP method, considering a large sample size may encompass "cold-called" respondents that have a great tendency to give an arbitrary answer, thereby resulting in a high degree of inconsistency (Cheng and Li, 2002). Previous researchers who adopted AHP survey with a small sample size include Wong and Li (2008), who gathered ten experts in selecting criteria for an intelligent building system. Cheng and $\mathrm{Li}$ (2002) invited nine experts to undertake an AHP survey to test the comparability of critical success factors for construction partnering. Furthermore, eleven respondents completed an AHP survey conducted by Alwaer and Clements-Croome (2010) in identifying the key performance indicators related to sustainable intelligent buildings, while Lam and Zhao (1998) selected eight experts for a quality-of-teaching survey. Thus, AHP can be applied using a small number of experts when focusing on a specific issue and requires only the relevant experts providing valuable insights into an empirical inquiry (Cheng and $\mathrm{Li}, 2002$ ). However, this sample size limits the representativeness of the results, reflecting the weightings of the experts selected, rather than being representative of the wide industry or other key stakeholder group, such as government or non-governmental organisations.

The selection of ten experts in this study was based on several capabilities, namely, accredited professional in sustainable assessment, with at least ten years of working experience in the field of sustainable and green building, and possesses extensive knowledge and experience on the refurbishment of non-domestic buildings. A consent form was sent to the prominent experts to obtain their consent to participate in the survey. A questionnaire and 
a covering letter were distributed by e-mail to the experts. The experts were given two weeks to complete the survey before a gentle reminder was made. Ten returned questionnaires were received for analysis. The data were entered into the Expert Choice software for analysis. The consistency level of the collected questionnaire showed an acceptable level of consistency with an index $<0.1$, as defined by Saaty (1994).

\subsection{Validation and data collection}

Expert interviews were conducted with seven industry experts to validate the weighting results. Qualitative interview is appropriate for verification purpose because it provides further explanation and clarification on the results and thus, allows collecting detailed information from the interviewees. The interviewees were selected if they (a) are accredited GBI facilitators, (b) have at least ten years of working experience in the construction industry, (c) have practical experience in refurbishment projects, and (d) possesses sufficient knowledge in green assessment and sustainable development. The data obtained from the interviews were analysed by manual content analysis.

\section{Proposed Malaysian Refurbishment Assessment Scheme (MRAS)}

The development of the proposed MRAS includes: (a) a weighting system for the assessment themes, (b) allocation of credit allocation to each assessment sub-theme, (c) rating formulas, and (d) a classification system.

\subsection{Weighting system for assessment themes}

The software Expert Choice 11 was used to analyse the AHP results. As explained earlier, the CR for this study was 0.07, as shown in Figure 3, which was less than the upper limit of 0.10 recommended to demonstrate consistency using this methodology. Hence, the result was reliable and consistent. Weightings of the different themes were extracted from pairwise comparison of the relative importance of all assessment themes by use of Expert Choice software. The pairwise comparison indicated that energy and IEQ were of top 
priorities to the representatives of the Malaysian built environment that were surveyed with weighting coefficients of 0.208 and 0.182, respectively, as illustrated in Figure 4.

\section{Insert Figure 3}

\section{Insert Figure 4}

\subsection{Credit and score allocation for the assessment sub-themes}

The MRAS adopted a credit scoring system. Credits were awarded for each subtheme under each of the 14 assessment themes depending on to performance specific criteria. As illustrated in Figure 5, the energy theme consisted of 12 sub-themes. The mean value for each sub-theme was generated after obtaining the results from the Delphi process that was conducted in the previous stage. If the mean value of the sub-theme exceeded 3.0, then the sub-theme was considered relevant to the practices involved in refurbishment projects. A three-level credit allocation was applied to differentiate among these sub-themes (Alyami and Rezgui, 2015; Garg et al., 2012). One credit was allocated if the mean value was between 3.0 and 4.0; two credits were awarded if the mean value was between 4.0 and 4.5; three credits were given if the mean value was more than 4.5. For example, the mean value for the energy performance of the heating, ventilation, and air conditioning (HVAC) system was 4.7; hence, three credits were awarded for this sub-theme. Therefore, as illustrated in Figure 5, five subthemes were awarded one credit; four sub-themes were allocated two credits; and three subthemes were given three credits. The total available credits for energy were 22, as presented in Table 2. A total of 153 credits were available for all assessment sub-themes, as provided in Table 2.

\section{Inset Figure 5}

\section{Insert Table 2}

\subsection{Rating formulas}

The following formula is applied to determine the total score achieved for a refurbished building: 


$$
\mathrm{S}=\frac{\mathrm{CS}}{\mathrm{AC}} \times \omega \times 100 \%
$$

where

S: Score for assessment theme

CS: Credit scored

AC: Available credits

$\omega$ : Weighting coefficient

The proportion of the available credits obtained under each of the themes was multiplied by the weighting coefficient for the relevant assessment themes using this formula. The scores for the 14 assessment themes were calculated by this formula, which resulted in 14 individual rating scores for the refurbishment project. The total score for the 14 assessment themes was then summed to provide an overall rating for the building within a maximum of 100 credits available. Accordingly, a single score was generated and reflected the sustainability level of the refurbished buildings.

\subsection{The rating classification system}

A short survey was conducted during an academic built environment conference to determine a suitable classification system for the MRAS. Three types of classification were proposed, namely, number of stars (1 star, 2 stars, etc.), type of stones (diamond, emerald, ruby, sapphire), and type of metals (platinum, gold, silver, bronze). The purpose of conducting this survey was to obtain public perception on the most popular classification system. Over 100 conference attendees participated in this survey, and 75 questionnaires were returned. The results revealed that the type of metals was rated most highly among the choices. Thus, this study adopted the type of metals as a classification system, as shown in Table 3.

\section{Insert Table 3}


Refurbishment remains unpopular in Malaysia, therefore, this study proposed $30 \%$ as the minimum score to achieve certification to promote refurbishments. This study aimed to encourage large number of buildings to be rated and certified by the MRAS with a less stringent certified score. A score of $75 \%$ was proposed as the minimum requirement for a "platinum" award for the MRAS in order to motivate more refurbishment projects to aspire to this level as compared with other assessment schemes that set 80\% (LEED and MyCREST) or $85 \%$ (BREEAM and GBI) as a requirement for the highest award level.

In the MRAS, buildings rated above $30 \%$ were considered "certified" because this is the lowest level of meeting primary criteria, buildings rated above $45 \%$ were awarded "bronze", buildings rated above 55\% were as classified "silver", buildings rated above 65\% were awarded "gold", and buildings rated above 75\% were awarded "platinum".

\section{Discussion}

The results of the weightings derived using the AHP has helped establish the further development of the MRAS. Thus, the proposed MRAS acts as a rating tool for refurbishment, as demonstrated in Figure 6. The assessment assessors are required to evaluate the performance of the refurbished buildings against a set of assessment themes and sub-themes and then obtain an overall score, which will be classified as certified, bronze, silver, gold or platinum on the basis of a rating classification system. Interview validation results revealed that the interview experts agreed with the proposed rating and classification system. One of the interviewees highlighted that proposing a less stringent score to achieve the pass or "certified" award could help motivate the industry to apply for the MRAS certification. Refurbishment assessment schemes are currently lacking in Malaysia because refurbishment practices are unpopular due to the cost. However, lessons learned from the United Kingdom and the United States indicate that the refurbishment of existing buildings is a good strategy to achieve sustainability and carbon reduction targets for the Malaysian built environment. The majority of the interviewees mentioned that the MRAS could be proposed to a relevant sustainability association to raise the awareness of the potential for practicing sustainable refurbishment in Malaysia. The refinement or complementing of the existing schemes by use of the relevant proposed assessment themes and sub-themes specific for refurbished buildings in Malaysia would be advisable. 
The results of the surveys and interviews revealed that energy and IEQ are the most critical assessment themes to the stakeholders that took part in the AHP with weighting coefficients of 0.208 and 0.182 , respectively. High credits are therefore allocated for the assessment of energy and IEQ in the MRAS. These findings were supported by interview experts during validation because these two assessment themes are the main themes relevant to the Malaysian built environment. Existing buildings in Malaysia are dominated with old and obsolete buildings that are energy inefficient and have poor ventilation. Inevitably, the assessment of energy efficiency in these existing old buildings becomes a crucial measure. The need for improving the energy performance of old buildings becomes obvious because old existing buildings were not necessarily built to high standards of sustainability. As shown in Figure 6, MRAS allocated high credits to the sub-themes of improving the energy performance of the HVAC systems and the building envelope, such as cladding. This finding is supported by Wang et al. (2014), who stated that inefficient HVAC systems and building envelopes are often found in existing buildings with high-energy consumption.

Ruparathna et al. (2016) suggested that upgrading the existing HVAC system to an energy efficient technology is a viable route to improve the energy performance of existing buildings. In Malaysia, the highest energy consuming component in commercial buildings is air-conditioning equipment which is responsible for $57 \%$ of their energy consumption (Saidur, 2009). Thus, improving existing HVAC system contributes to energy improvement and commensurate $\mathrm{CO}_{2}$ reductions associated with the building's electricity use as supported by Ding et al. (2010) and Zhao et al. (2009). The building envelope is another important element that requires consideration during refurbishment (Asadi et al., 2012). Building insulation should be improved to reduce the heat gain from the Malaysian buildings to maintain its thermal performance. Such an improvement can provide significant reductions in airconditioning load for enhancing building energy efficiency.

The MRAS allocates 30 available credits for IEQ with six sub-themes, namely, noise and acoustics, lighting and illumination, thermal comfort, ventilation, contamination level, and odour level. The assessment of IEQ is crucial during refurbishment, as explained by Zhao et al. (2009), because it directly affects the comfort, productivity and health of the building occupants. The majority of people spend most of their time indoors and hence, various aspects of the indoor environment can affect the well-being of the building occupants. Malaysia is situated in a tropical climate region, which is hot and humid. The majority of buildings in Malaysia are equipped with air-conditioning and ventilation systems to maintain 
a thermally comfortable indoor environment. However, obsolescence and deterioration cause the existing equipment to become unfit for the occupants which result in discomfort. The rapid development in the city area especially Kuala Lumpur, introduces issues such as noise and air pollution which affect the well-being and health performance of occupants. Zamani et al. (2013) investigated the indoor air quality and the prevalence of sick building syndrome (SBS) in Malaysian buildings. They determined that the prevalence of SBS in old buildings in Malaysia is higher and the level of indoor air pollutants in old buildings is higher than in new buildings. The IEQ of the existing buildings should thus be improved during refurbishment.

The majority of the assessment schemes available do not include the assessment of economic, social, and cultural themes, which is contrary to the ultimate principle of sustainable development. This study indicated that they are relevant assessment themes for refurbishment projects. The majority of the interviewees stated that most of the existing schemes focus on the environmental assessment, and less emphasis is given on the economic and social aspects. They mentioned that a strong linkage exists among these aspects, and the pillar of sustainability includes social and economic aspects, apart from environmental aspects. Therefore, all these relevant assessment themes are necessary to incorporate for refurbishment, as proposed in the MRAS, while acknowledging that without a clear economic case, the refurbishment would not go ahead. The GBI and MyCrest schemes currently used to appraise new buildings in Malaysia do not provide sufficient evaluation of the social and cultural assessment themes. In conducting a social evaluation, public open space and building amenities should be included for the benefit of building occupants to cater for their social well-being (Kellett and Rofe, 2009). Furthermore, an assessment of the cultural aspects of the building is important to preserve and maintain the local and regional heritage during refurbishment. Sustainable development results in not only energy and resource conservation but also increased well-being of occupants.

In terms of economic aspect, Zhao et al. (2009) stressed that economic aspect is one of the most critical factors to be included during building refurbishment. However, this aspect is not covered sufficiently in GBI and MyCrest. Thus, this assessment theme is proposed in MRAS because it is relevant for refurbishment. For a refurbishment project, the refurbishment options and the implementation cost should be evaluated. The latter are a concern if there is a limited budget for refurbishment. Ding (2008) explained that sustainable buildings are potentially costly to construct. However, Bruce et al. (2015) argued that 
refurbishing existing buildings offers a significant potential to achieve energy efficiency and predictable financial benefits. It could provide long-term saving potential such as refurbished buildings are healthier and would lead to less employee absenteeism, increasing employee's productivities and thereby boosting the overall profitable of the business occupiers (Clements-Croome, 2006). Refurbish the existing buildings can increase the quality grade, the rental and capital value of the buildings. Therefore, economic evaluation should be included in MRAS to attain economic sustainability.

Compared with other assessment schemes, the proposed MRAS includes an assessment of not only the environmental impacts of the refurbishment project but also the economic and social aspects. As highlighted by several authors (Ding, 2008; Raslanas et al., 2013), the assessment of economic and social aspects is not covered in most of the existing assessment schemes. The empirical findings of this study indicate that the assessment of refurbishment needs to include economic and social themes. Therefore, this study includes these critical assessment themes in the MRAS.

\section{Insert Figure 6}

\section{Conclusion and policy implications}

Refurbishment can provide numerous positive effects on the natural environment, especially the reduction in greenhouse gas emissions and energy consumption if conducted to high sustainability standards. The refurbishment of existing buildings can revolutionise the building sector to help achieve sustainable development. This study supports the development of a refurbishment scheme for Malaysia to assess refurbished buildings and promote sustainable refurbishment. This study adopts the AHP to rate the priority of the assessment themes by assigning scores to each one in order to develop the rating and scoring for the proposed scheme.

The proposed MRAS provides a holistic assessment approach that considers the Malaysian built environment context because it was conducted using a systematic approach including a literature review, Delphi questionnaire survey, and the AHP method. The significant findings of the proposed MRAS are the value of weighting and scoring system developed to assess the performance themes and sub-themes for refurbished buildings. 
Although similarities regarding the assessment themes and sub-themes exist between the proposed MRAS and previous assessment tools, the MRAS covers the additional assessment themes, such as economic, social and cultural aspects, which ensure maximum beneficial social and economic impacts not merely concentrating on the environmental aspect of refurbishment.

There is a distinct lack of standards or regulations for building refurbishment practices in Malaysia. Hence, it is important for policy makers and practitioners in Malaysia such as Ministry of Energy-Green Technology and Water (KeTTHA) to be able to make use of the proposed framework. It is also a possibility to steer selected Malaysian policies and standards, such as the Environment Quality Act 1974 (Act 127), MS ISO 14001: 2015 and MS ISO 50001: 2011, in the areas of environmental and energy management and improvement towards an effective practice in buildings refurbishment. The existing policies and standards should incorporate relevant requirements and criteria as reported in this study to govern the refurbishment practices and procedures. Thus, this study provides an insights and guideline that help to direct the government to formulate, adopt, evaluate or update the existing policies and standards. It is recommended that the government should formulate a refurbishment guidance for existing building stocks. Moreover, results of this research provide the foundation for green building associations, such as Malaysia Green Building Confederation (MGBC), GBI and MyCREST, to realise the inadequate assessment themes on existing environmental assessment schemes. It is crucial to consider economic, social and cultural perspectives in support of a comprehensive refurbishment practice. This means that focusing on a single dimension (e.g. environmental) is less likely to deliver the desired sustainability improvement. Decision and policy makers need to be aware that the refurbishment process and practice involves various aspects of sustainability in order to lead the building industry in embracing responsible measures that would help to develop a sustainable built environment for Malaysia.

The proposed refurbishment scheme can be used by various stakeholders such as the government, developers and project practitioners to assess refurbished buildings, which in turn promote building refurbishment assessment for ensuring best practices. Other developing countries with similar environmental and social priorities, and without refurbishment sustainability appraisal schemes can also adopt this scheme for developing a new refurbishment scheme in view of the importance of refurbishment. Through this initiative, the local authority could start practising building refurbishment for environmental benefit. For 
those countries with a refurbishment scheme, the findings can be referred to by the scheme developers or policy makers to refine or improve their refurbishment schemes by incorporating the relevant and critical assessment themes and sub-themes, especially economic, social, and cultural aspects. By doing this, it will integrate the major sustainability pillars equally.

Although the study has achieved the aim stated in the introduction, the study is not conducted without limitations. The sample size is considered small, and a limited number of experts from various backgrounds are identified for the surveys. This limitation is also due to a lack of expertise in this area in Malaysia. Thus, this study is considered exploratory and representative of the opinions of the survey respondents. The developed MRAS, assessment themes, and sub-themes in this study can improve the understanding of practitioners in assessing refurbishment, which in turn can allow further comparison and discussion to improve or refine the framework by use of other research methods, such as the Analytic Network Process (ANP) (Saaty, 2013). Further research can focus on great integration across various disciplines in the industry, as well as other stakeholders, such as government representatives, building users, and non-governmental organisations to generate a consensus in developing the assessment themes, sub-themes and their weightings for refurbishment projects. The participation of different experts in the AHP survey can lead to different relative weightings on the assessment themes and sub-themes. Furthermore, this study can lead to future research in other countries with similar climatic, social, and economic conditions to Malaysia or the development of a refurbishment scheme for historical buildings. Historic buildings in Malaysia provoke a demand for refurbishment due to their historical and architectural merits.

\section{Acknowledgment}

This research is supported by the British Council Newton-Ungku Omar Institutional Links Fund (172726659) through the University of Malaya Institute of Research Management and Monitoring (IF009-2015 and RK005-2015).

\section{References}


Ahmed, A. Z., Nayar, C.V., 2008. Integrating sustainable energy in buildings: a case study in Malaysia. Paper presented at the FAU Conference, Copenhagen, Denmark.

Al-Harbi, K. M. A., 2001. Application of the AHP in project management. International journal of project management, 19 (1), 19-27.

Ali, H. H., Al Nsairat, S. F., 2009. Developing a green building assessment tool for developing countries-Case of Jordan. Building and Environment, 44 (5), 1053-1064.

Alwaer, H. \& Clements-Croome, D. J., 2010. Key performance indicators (KPIs) and priority setting in using the multi-attribute approach for assessing sustainable intelligent buildings. Building and Environment, 45 (4), 799-807.

Alyami, S. H., Rezgui, Y., 2012. Sustainable building assessment tool development approach. Sustainable Cities and Society. 5, 52-62.

Alyami, S. H., Rezgui, Y., Kwan, A., 2015. The development of sustainable assessment method for Saudi Arabia built environment: weighting system. Sustainability Science, $10(1), 167-178$.

Alyami, S. H., Rezgui, Y., Kwan, A., 2013. Developing sustainable building assessment scheme for Saudi Arabia: Delphi consultation approach. Renewable and Sustainable Energy Reviews, 27, 43-54.

Aminbakhsh, S., Gunduz, M., Sonmez, R., 2013. Safety risk assessment using analytic hierarchy process (AHP) during planning and budgeting of construction projects. Journal of safety research, 46, 99-105.

Asadi, E., Da Silva, M. G., Antunes, C. H., Dias, L., 2012. Multi-objective optimization for building retrofit strategies: a model and an application. Energy and Buildings. 44, 81-87.

BREEAM, 2015. BREEAM International Refurbishment and Fit-out. http://www.breeam.com/refurbishment-and-fit-out (accessed 08.07.2015).

Bruce, T., Zuo, J., Rameezdeen, R., Pullen, S., 2015. Factors influencing the retrofitting of existing office buildings using Adelaide, South Australia as a case study. Structural Survey. 33 (2), 150-166.

Building and Construction Authority (BCA), 2012. Green Mark homepage. http://www.bca.gov.sg/GreenMark/green_mark_themes.html (accessed 24.08.2015).

CASBEE, 2015. CASBEE homepage. http://www.ibec.or.jp/CASBEE/english/index.htm (accessed 08.07.2015).

Chang, C. Y., Lin, H. T., Ho, M. C., 2012. Sustainability assessment tool of green building renovation in Taiwan: an introduction to EEWH-RN. International Journal of Sustainable Construction, 1 (1), 25-31.

Cheng, E. W. L., Li, H., 2002. Construction partnering process and associated critical success factors: quantitative investigation. Journal of management in engineering, 18 (4), 194202. 
Cheung, S. O., Lam, T. I., Leung, M. Y., Wan, Y. W., 2001. An analytical hierarchy process based procurement selection method. Construction Management \& Economics, 19 (4), 427-437. doi: 10.1080/014461901300132401

Chew, M. Y. L., Das, D., 2008. Building grading systems: A review of the state-of-the-art. Architectural Science Review. 51 (1), 3-13.

Chowdhury, S., Sumita, U., Islam, A., Bedja, I., 2014. Importance of policy for energy system transformation: Diffusion of PV technology in Japan and Germany. Energy Policy, 68, 285-293.

Clements-Croome, D., 2006. Creating the Productive Workplace, $2^{\text {nd }}$ edition, Spon, London.

Cole, R.J., 2005. Building environmental assessment methods: redefining intentions and roles, Building Research and Information, 33 (5), 455-467.

Construction Industry Development Board (CIDB), 2013. Malaysian Carbon Reduction \& Environmental Sustainability Tool - MyCREST. https://www.cidb.gov.my/cidbv4/ index.php?option=com_content\&view=article\&id=1110:malaysian-carbon-reductionenvironmental-sustainability-tool-mycrest\&catid=37\&Itemid=275\&lang=en (accessed 08.07.2015).

Construction Specifications Institute (CSI), 2013. The CSI Sustainable Design and Construction Practice Guide. Wiley.

Ding, G. K. C., 2008. Sustainable construction-The role of environmental assessment tools. Journal of environmental management, 86 (3), 451-464.

Ding, Y., Tian, Z., Zhu, N., 2010. The retrofit of industrial air-conditioning system on energy efficiency and emission reduction. Energy and Buildings, 42 (6), 955-958.

Department of Environment (DOE), 2010. Buildings Energy Data Book, Office of Energy Efficiency and Renewable Energy. Washington, DC, USA: U.S. Department of Energy.

Economic Planning Unit (EPU), 2015. Eleventh Malaysia Plan 2016-2020. http://rmk11.epu.gov.my/index.php/en/ (accessed 17.09.2015)

Fong, P. S. W., Choi, S. K. Y., 2000. Final contractor selection using the analytical hierarchy process. Construction Management \& Economics, 18 (5), 547-557.

Garg, R., Rahman, Z., Qureshi, M. N., Kumar, I., 2012. Identifying and ranking critical success factors of customer experience in banks: An analytic hierarchy process (AHP) approach. Journal of Modelling in management, 7 (2), 201-220.

Green Building Council Australia (GBCA), 2014. Green Star - Design \& As Built. https://www.gbca.org.au/green-star/green-star-design-as-built/ (accessed 24.08.2015).

Green Building Index (GBI), 2011, Green Building Index Assessment Criteria for Nonresidential Existing Building. http://new.greenbuildingindex.org/Files/Resources/GBI\% 20Tools/GBI\%20NREB\%20Non-Residential\%20Existing\%20Building\%20Tool\%20V 1.1\%20Final.pdf (accessed 24.08.2015). 
Green Building Label (GBL), 2013. Green Building Label System. http://green.abri.gov.tw/art-en.php?no=61\&SubJt=Green+Building+Label (Accessed 24.08.2015).

Haapio, A., Viitaniemi, P., 2008. A critical review of building environmental assessment tools. Environmental impact assessment review, 28 (7), 469-482.

Haute Qualité Environnementale (HQE), 2013. HQE homepage. http://www.behqe.com/cerway/essentials (accessed 20.08.2016).

Hong Kong Green Building Council (HKGBC), 2012. BEAM Plus V1.2 for New Buildings. https://www.hkgbc.org.hk/upload/beamdocuments/BEAM-Plus-NB-1-2-Manual.pdf (accessed 24.08. 2015).

Kamaruzzaman, S. N., Lou, E. C. W., Zainon, N., Mohamed Zaid, N. S., Wong, P. F., 2016. Environmental assessment schemes for non-domestic building refurbishment in the Malaysian context. Ecological Indicators, 69, 548-558.

Kellett, J. E., Rofe, M. W., 2009. Creating Active Communities: how Can Open and Public Spaces in Urban and Suburban Environments Support Active Living?: A Literature Review. Institute for Sustainable Systems and Technologies, University of South Australia.

Komeily, A., Srinivasan, R. S., 2015. A need for balanced approach to neighborhood sustainability assessments: A critical review and analysis. Sustainable Cities and Society, 18, 32-43.

Kumar, R., Madhu, E. Dahiya, A., Sinha, S., 2015. Analytical hierarchy process for assessing sustainability: Indicators of public transportation systems, pedestrians and feeder services in developing countries. World Journal of Science, Technology and Sustainable Development, 12 (4), 281-293.

Lam, K., Zhao, X., 1998. An application of quality function deployment to improve the quality of teaching. International Journal Quality Reliability Manage, 15 (4), 389-413.

Lee, W. L., 2013. A comprehensive review of metrics of building environmental assessment schemes. Energy and Buildings, 62, 403-413.

Lester, T. W., 2013. Dedicating new real estate transfer taxes for energy efficiency: A revenue option for scaling up Green Retrofit Programs. Energy policy, 62, 809-820.

Loo, R., 2002, The Delphi method: a powerful tool for strategic management. Policing: An International Journal of Police Strategies \& Management, 25, 4, 762-769.

Michael, F. L., Noor, Z. Z., Figueroa, M. J., 2014. Review of urban sustainability indicators assessment-Case study between Asian countries. Habitat International, 44, 491-500.

Mickaityte, A., Zavadskas, E. K., Kaklauskas, A., Tupenaite, L., 2008. The concept model of sustainable buildings refurbishment. International Journal of Strategic Property Management, 12 (1), 53-68.

National Refurbishment Centre (NRC), 2011, Refurb or retrofit? http://www.rethinkingrefurbishment.com/page.jsp?id=150 (accessed 19.12.2016) 
Oh, K. H., 1974, Forecasting through hierarchical Delphi. The Ohio State University.

Pill, J., 1971, The Delphi method: substance, context, a critique and an annotated bibliography, Socio-Economic Planning Sciences, 5, 1, 57-71.

Pombo, O., Rivela, B., Neila, J., 2015. The challenge of sustainable building renovation: assessment of current themes and future outlook. Journal of Cleaner Production, 123, 113.

Rahmat, I., Torrance, V. B., Ezanee, A. H., 2003. Refurbishment cycles and the management of refurbishment project. UiTM Research Centre, Shah Alam, Selangor, Malaysia.

Ramanathan, R., 2001. A note on the use of the analytic hierarchy process for environmental impact assessment. Journal of environmental management, 63 (1), 27-35.

Raslanas, S., Stasiukynas, A., Jurgelaitytè, E., 2013. Sustainability assessment studies of recreational buildings. Procedia Engineering, 57, 929-937.

Ruparathna, R., Hewage, K., Sadiq, R., 2016. Improving the energy efficiency of the existing building stock: A critical review of commercial and institutional buildings. Renewable and Sustainable Energy Reviews, 53, 1032-1045.

Saaty, T. L., 1980. The analytic hierarchy process: planning, priority setting, resource allocation. Pittsburgh PA: University of Pittsburgh.

Saaty, T. L., 1982. Decision making for leaders: The analytical hierarchy process for decisions in a complex world, Lifetime Learning Publication, A division of Wadsworth, Belmont, CA.

Saaty, T. L., 1994. Fundamentals of decision making and priority theory with the analytic hierarchy process: RWS Publications, Pittsburgh.

Saaty, T. L., 2000. Fundamentals of decision making and priority theory with the analytic hierarchy process (Vol. 6). Pittsburg: RWS Publications.

Saaty, T. L., 2013. Analytic network process, Encyclopedia of operations research and management science, 64-72.

Saidur, R., 2009. Energy consumption, energy savings, and emission analysis in Malaysian office buildings. Energy Policy, 37 (10), 4104-13.

Sharifi, A., Murayama, A., 2013. A critical review of seven selected neighborhood sustainability assessment tools. Environmental Impact Assessment Review, 38, 73-87.

Sharifi, A., Murayama, A., 2015. Viability of using global standards for neighbourhood sustainability assessment: Insights from a comparative case study. Journal of Environmental Planning and Management, 58 (1), 1-23.

Sinou, M., Kyvelou, S., 2006. Present and future of building performance assessment tools. Management of Environmental Quality: An International Journal, 17 (5), 570-586.

Tanguay, G. A. , Rajaonson, J. , Lefebvre, J. F., Lanoie, P., 2010. Measuring the sustainability of cities: an analysis of the use of local indicators. Ecological Indicators 10 (2), 407-418. 
The Chartered Institute of Building (CIOB), 2011. Buildings under refurbishment and retrofit. http://www.carbonaction2050.com/sites/carbonaction2050.com/files/documentattachment/Buildings\%20under\%20Refurb\%20and\%20Retrofit.pdf (accessed 17.03.2016).

The Malaysian Reserve, 2015. Plan to reduce greenhouse emission to 45\% of GDP. Retrieved from http:/www.themalaysianreserve.com/new/story/plan-reduce-greenhouse-emission -45-gdp (accessed 02.04.2016).

United Nations Environment Programme (UNEP), 2015. Why buildings. http://www.unep.org/sbci/AboutSBCI/Background.asp (accessed 14.04.2016).

United Nation Framework Convention on Climate Change (UNFCCC), 2015. Adoption of The Paris Agreement, https://unfccc.int/resource/docs/2015/cop21/eng/109r01.pdf, (accessed 19.12.2016)

United State Green Building Council (USGBC), 2011. USGBC homepage. http://www.usgbc.org/ (accessed 08.07.2015).

Wang, Z. X., Ding, Y., Geng, G., Zhu, N., 2014. Analysis of energy efficiency retrofit schemes for heating, ventilating and air-conditioning systems in existing office buildings based on the modified bin method. Energy Conversion and Management, 77, 233-242.

Wong, J. K. W., Li, H., 2008. Application of the analytic hierarchy process (AHP) in multicriteria analysis of the selection of intelligent building systems. Building and Environment, 43 (1), 108-125.

Yang, P. J., He, G., Mao, G. Z., Liu, Y., Xu, M. Z., Guo, H. C., Liu, X., 2013. Sustainability needs and practices assessment in the building industry of China. Energy Policy, 57, 212-220.

Zamani, M. E., Jalaludin, J., Shaharom, N., 2013. Indoor air quality and prevalence of sick building syndrome among office workers in two different offices in Selangor. American Journal of Applied Sciences, 10 (10), 1140.

Zhao, J., Zhu, N., Wu, Y., 2009. Technology line and case analysis of heat metering and energy efficiency retrofit of existing residential buildings in Northern heating areas of China. Energy policy, 37 (6), 2106-2112.

Zhou, Z. H., Zhang, S. Z., Wang, C. D., Zuo, J., He, Q., Rameezdeen, R., 2016. Achieving energy efficient buildings via retrofitting of existing buildings: a case study. Journal of Cleaner Production, 112, 3605-3615. 


\begin{tabular}{|c|l|l|}
\hline $\begin{array}{c}\text { Intensity of } \\
\text { importance }\end{array}$ & \multicolumn{1}{|c|}{ Definition } & \multicolumn{1}{|c|}{ Explanation } \\
\hline 1 & $\begin{array}{l}\text { Equal importance of both } \\
\text { element }\end{array}$ & $\begin{array}{l}\text { Two activities contribute equally to the } \\
\text { objectives }\end{array}$ \\
\hline 3 & $\begin{array}{l}\text { Moderate importance of } \\
\text { one over another }\end{array}$ & $\begin{array}{l}\text { Experience and judgement slightly favoured } \\
\text { one activity over another }\end{array}$ \\
\hline 5 & Strong importance & $\begin{array}{l}\text { Experience and judgement strongly favoured } \\
\text { one activity over another }\end{array}$ \\
\hline 7 & Very strong importance & $\begin{array}{l}\text { An activity is favoured very strongly over } \\
\text { another; its dominance demonstrated in } \\
\text { practice }\end{array}$ \\
\hline 9 & $\begin{array}{l}\text { Absolute importance } \\
\text { The evidence favouring one activity over } \\
\text { another is of the highest possible order of } \\
\text { affirmation }\end{array}$ \\
\hline $2,4,6,8$ & $\begin{array}{l}\text { Intermediate values } \\
\text { between the two adjacent } \\
\text { scale values }\end{array}$ & $\begin{array}{l}\text { Used to represent compromise between the } \\
\text { priorities listed above }\end{array}$ \\
\hline
\end{tabular}

Table 1: The AHP pairwise comparison scale (Saaty, 1980, p.54)

\begin{tabular}{|l|c|c|}
\hline \multicolumn{1}{|c|}{ Theme } & $\begin{array}{c}\text { Weighting } \\
\text { Coefficient }\end{array}$ & Available credits \\
\hline Energy & 0.208 & 22 \\
\hline IEQ & 0.182 & 30 \\
\hline Water & 0.132 & 11 \\
\hline Waste & 0.121 & 6 \\
\hline Material & 0.106 & 14 \\
\hline Transport & 0.060 & 10 \\
\hline Management & 0.046 & 11 \\
\hline Quality of services & 0.037 & 10 \\
\hline Sustainable Site & 0.033 & 6 \\
\hline Pollution & 0.021 & 9 \\
\hline Innovation & 0.017 & 5 \\
\hline Economics & 0.014 & 13 \\
\hline Social & 0.012 & 3 \\
\hline Cultural & 0.012 & 153 \\
\hline \multicolumn{1}{|c|}{ TOTAL } & $\sum 1.0$ & 3 \\
\hline
\end{tabular}

Table 2: Weighting coefficient and credit available for MRAS 


\begin{tabular}{|l|c|}
\multicolumn{1}{|c|}{ Classification } & Score \\
\hline Platinum & $\geq 75 \%$ \\
\hline Gold & $\geq 65 \%$ \\
\hline Silver & $\geq 55 \%$ \\
\hline Bronze & $\geq 45 \%$ \\
\hline Certified & $\geq 30 \%$ \\
\hline
\end{tabular}

Table 3: MRAS classification system 


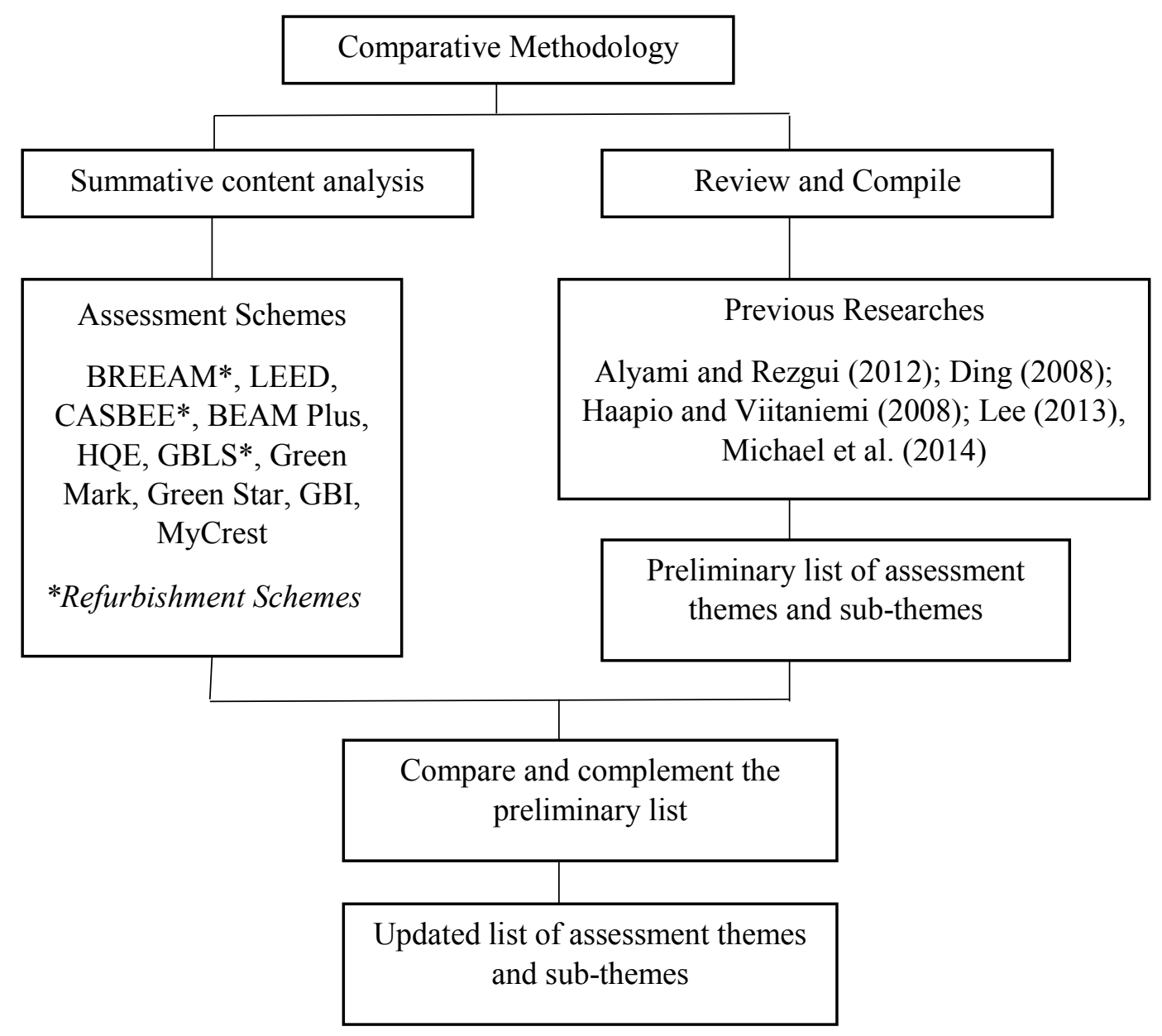

Figure 1 Process of generating a list of assessment themes and sub-themes

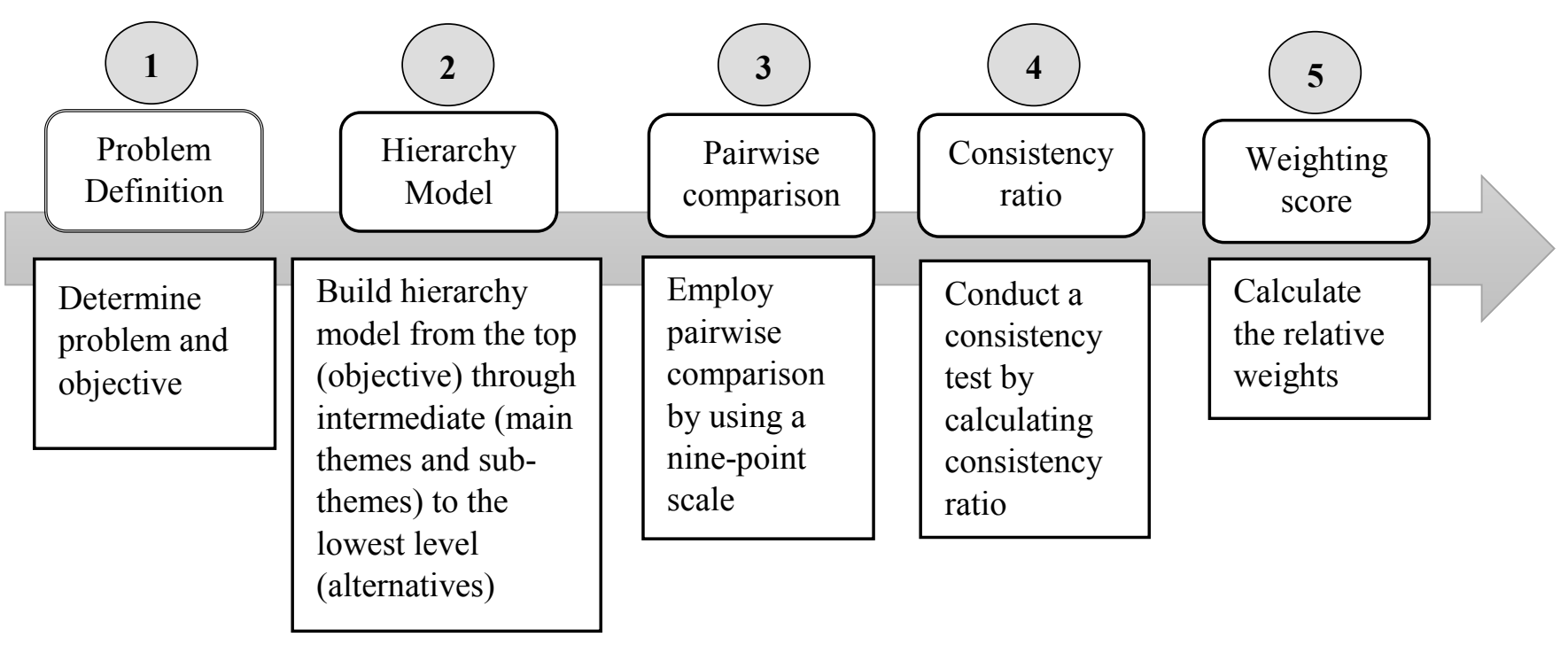

Figure 2: Five stages of AHP (Saaty, 1980) 


\begin{tabular}{|c|c|c|c|c|c|c|c|c|c|c|c|c|c|c|}
\hline & Energy & Indoor Eny $N$ & Manageme S & Sustainabl T & Transport & Water & Waste & Material & Pollution & Innovation & Economics & $\overline{\text { Social }}$ & Cultural & Quality of s \\
\hline Energy & & 1.88818 & 6.94589 & 6.96022 & 7.07949 & 2.42081 & 2.42081 & 2.70192 & 7.38405 & 7.25966 & 7.96229 & 7.86906 & 8.27469 & 5.83463 \\
\hline Indoor Environmental Quality & & & 5.75724 & 6.74563 & 5.27207 & 2.74822 & 2.59456 & 3.04762 & 6.26631 & 6.45407 & 7.16336 & 7.13388 & 7.08218 & 5.79248 \\
\hline Management & & & & 1.88818 & 1.96631 & 5.23816 & 4.95934 & 4.25951 & 4.68205 & 4.5415 & 4.70286 & 5.12893 & 5.18326 & 1.85406 \\
\hline Sustainable Site & & & & & 3.02801 & 6.11054 & 6.36846 & 6.38161 & 3.06735 & 3.33857 & 3.99371 & 3.86156 & 4.53587 & 1.07177 \\
\hline Transport & & & & & & 3.71743 & 4.06395 & 2.71297 & 4.45392 & 6.48074 & 6.28399 & 6.18786 & 6.28399 & 1.68084 \\
\hline Water & & & & & & & 1.47273 & 1.53367 & 6.86455 & 7.28611 & 6.97119 & 7.2711 & 7.36884 & 5.58703 \\
\hline Waste & & & & & & & & 1.23114 & 6.58142 & 6.96022 & 6.66989 & 6.75445 & 6.98558 & 4.72356 \\
\hline Material & & & & & & & & & 6.51217 & 6.05897 & 5.87502 & 5.8585 & 5.73647 & 5.19822 \\
\hline Pollution & & & & & & & & & & 1.91055 & 2.78078 & 3.38345 & 3.38345 & 3.0799 \\
\hline Innovation & & & & & & & & & & & 2.04767 & 2.38003 & 2.6564 & 3.98107 \\
\hline Economics & & & & & & & & & & & & 1.76173 & 1.23114 & 4.06395 \\
\hline Social & & & & & & & & & & & & & 1.49018 & 4.45392 \\
\hline Cultural & & 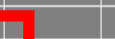 & & & & & & & & & & & & 4.90518 \\
\hline Quality of services & Incon: 0.07 & & & & & & & & & & & & & \\
\hline
\end{tabular}

Figure 3: Combined pairwise comparison matrix (generated from Expert Choice)

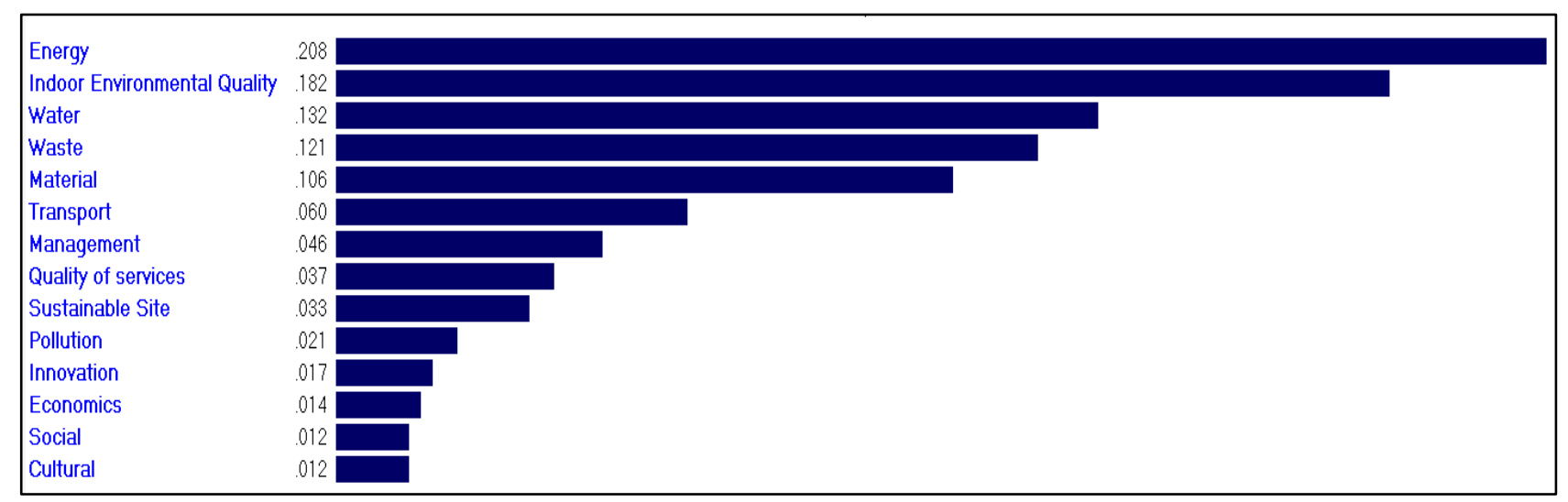

Figure 4: Prioritisation of the assessment themes, derived from pairwise comparison (generated from

Expert Choice) 


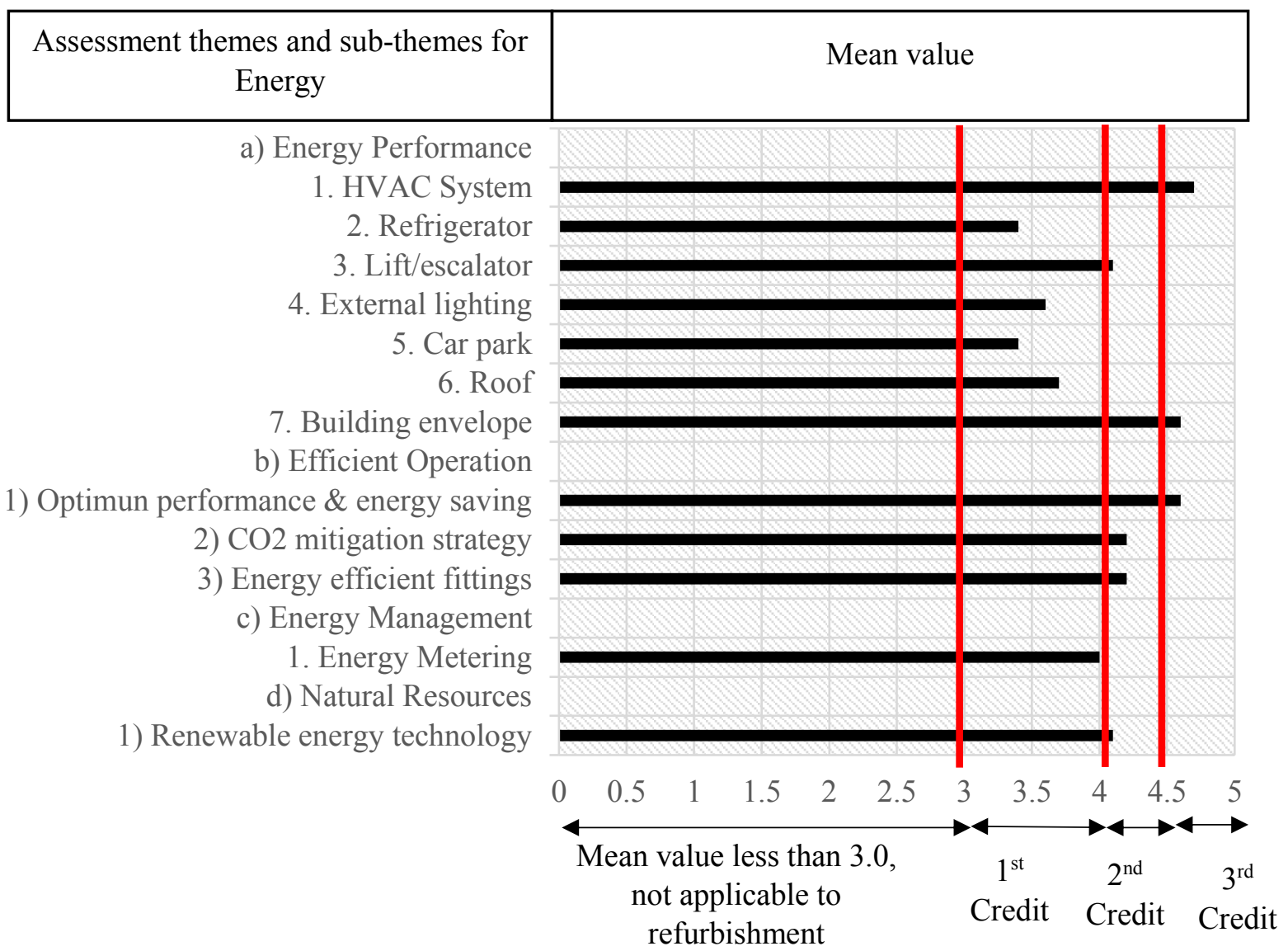

Figure 5: Credit allocation based on mean value for energy 


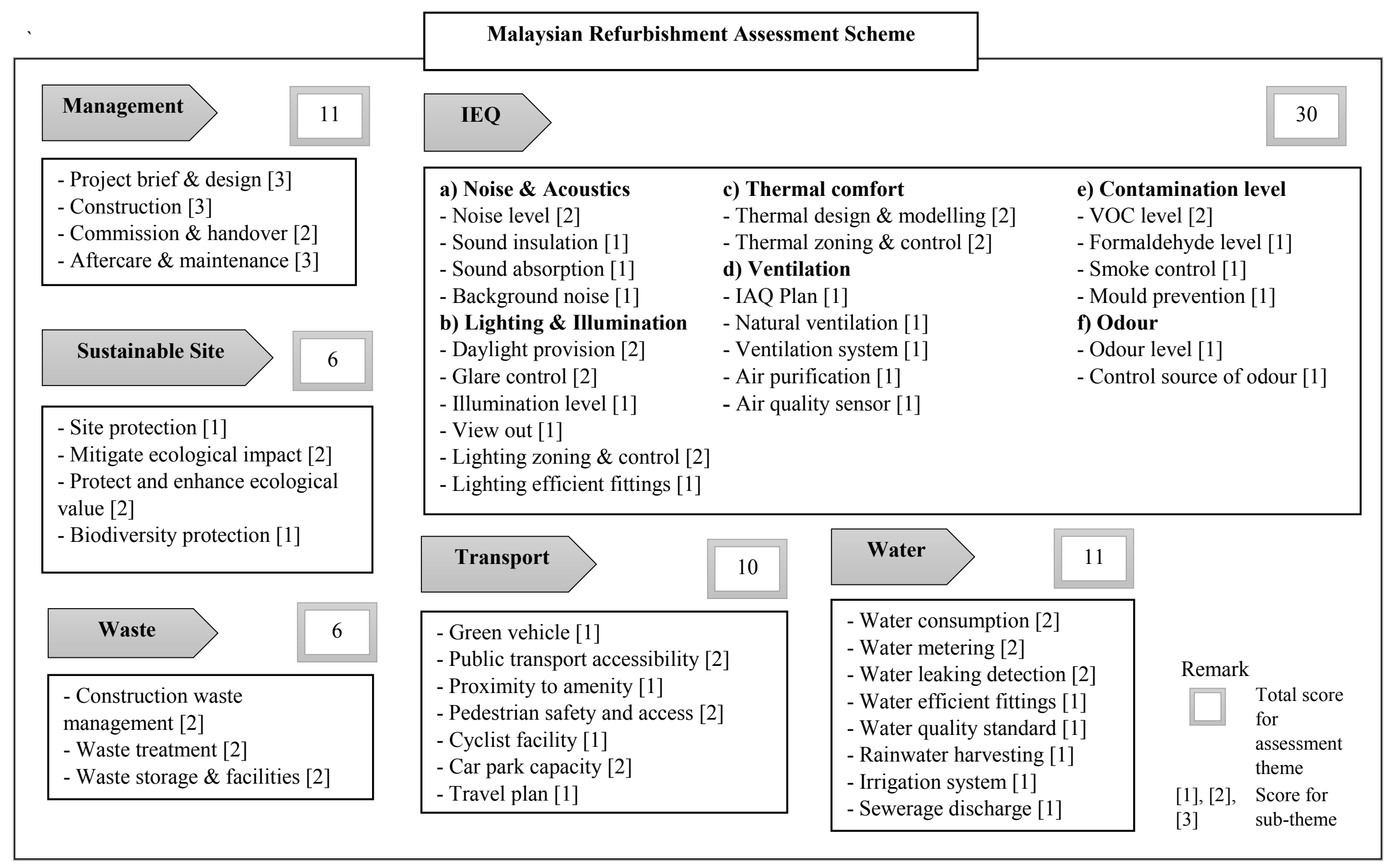

Figure 6: Proposed Malaysian Refurbishment Assessment Scheme 
Malaysian Refurbishment Assessment Scheme

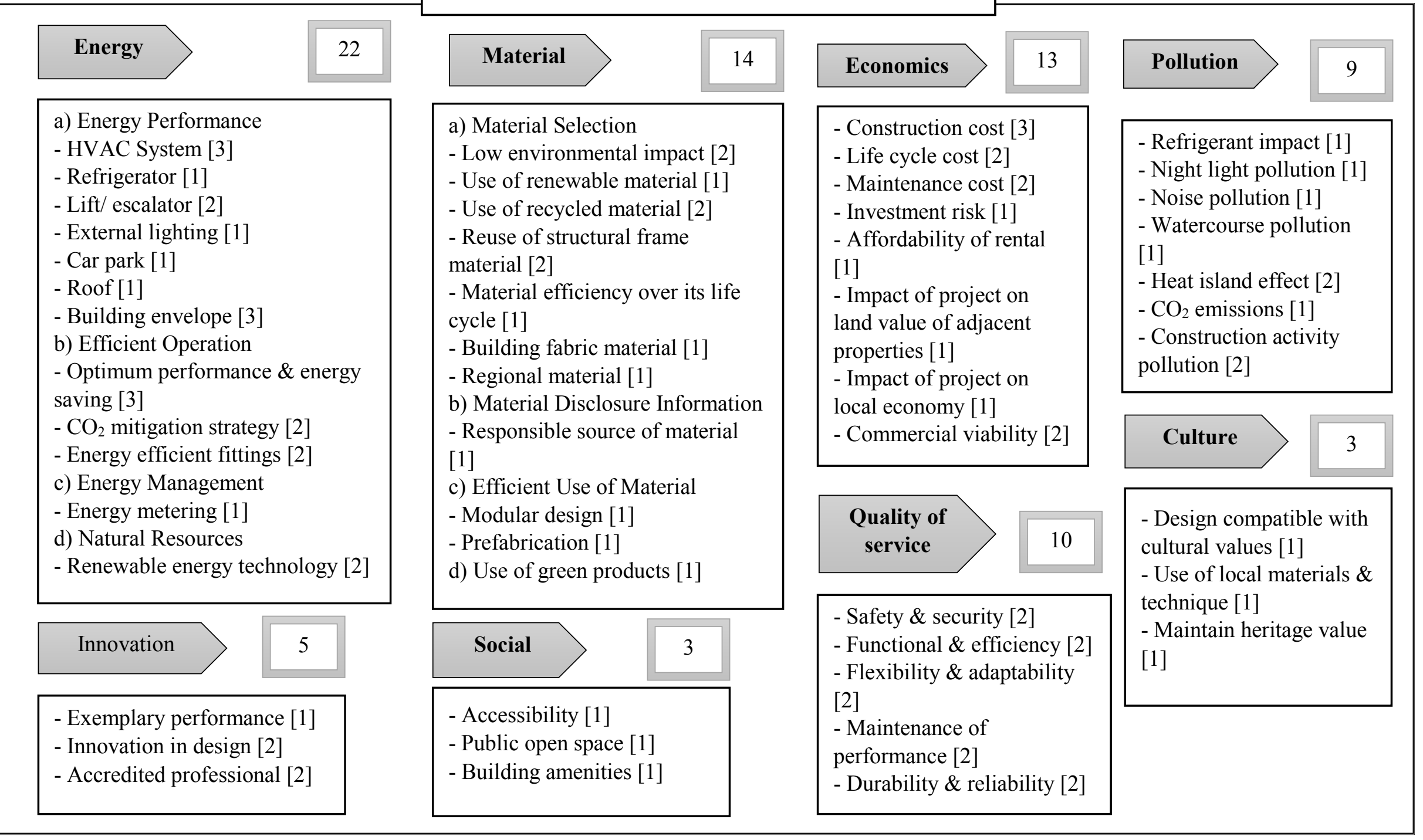

Figure 6: Proposed Malaysian Refurbishment Assessment Scheme (continued) 